\title{
Radar characterization of the basal interface across the grounding zone of an ice-rise promontory in East Antarctica
}

\author{
Kenichi MATSUOKA, ${ }^{1}$ Frank PATTYN, ${ }^{2}$ Denis CALLENS, ${ }^{1,2}$ Howard CONWAY ${ }^{3}$ \\ ${ }^{1}$ Norwegian Polar Institute, Fram Centre, Tromsø, Norway \\ E-mail: matsuoka@npolar.no \\ ${ }^{2}$ Laboratoire de Glaciologie, Université Libre de Bruxelles, Brussels, Belgium \\ ${ }^{3}$ Department of Earth and Space Sciences, University of Washington, Seattle, WA, USA
}

\begin{abstract}
Radar power returned from the basal interface along a $42 \mathrm{~km}$ long profile over an ice-rise promontory and the adjacent Roi Baudouin ice shelf, Dronning Maud Land, East Antarctica, is analyzed to infer spatial variations in basal reflectivity and hence the basal environment. Extracting basal reflectivity from basal returned power requires an englacial attenuation model. We estimate attenuation in two ways: (1) using a temperature-dependent model with input from thermomechanical ice-flow models; and (2) using a radar method that linearly approximates the geometrically corrected returned power with ice thickness. The two methods give different results. We argue that attenuation calculated using a modeled temperature profile is more robust than the widely used radar method, especially in locations where depth-averaged attenuation varies spatially or where the patterns of basal reflectivity correlate with the patterns of the ice thickness.
\end{abstract}

\section{INTRODUCTION}

Grounding zones are located between the most landward site of ice flexure from tidal movement and the most landward site where the ice reaches approximate hydrostatic equilibrium (Vaughan, 1994; Fricker and Padman, 2006). They are typically several kilometers long (Brunt and others, 2010), but can be as long as 20-30 km depending on the strength of tides and the elastic properties of ice (Sykes and others, 2009). Because the flow of upstream ice is strongly controlled by the grounding zones (e.g. Schoof, 2007) there is strong motivation to improve understanding of conditions at the basal interface across the grounding zones.

Interpretation of basal conditions across grounding lines from radar data is complicated because the basal interface in the vicinity of grounding zones is subject to influences from ocean water, sediment-rich glacier meltwater from upstream, sediments and bedrock properties. For example, MacGregor and others (2011) examined radar power returned from the basal interface along 11 profiles across the Siple Coast (West Antarctica) grounding zone. Results showed no strong contrast in basal reflectivity, which was attributed to a thin $(>\sim 0.2 \mathrm{~m})$ water film that extended several kilometers upstream of the grounding zone.

Here we present radar data collected across an ice-rise promontory and the adjacent ice shelf in Dronning Maud Land, East Antarctica (Fig. 1). To derive a proxy of basal conditions, we calculated englacial attenuation using two different methods: one employs a widely used radar algorithm and the other uses a temperature-dependent attenuation model with input from thermomechanical iceflow models. We discuss the differences in basal conditions inferred from these methods.

\section{METHODS}

\section{Radar/GPS profiling}

A $42 \mathrm{~km}$ long profile was made from the ice-rise promontory to the adjacent ice shelf (Figs 1 and 2). We used a $5 \mathrm{MHz}$ ground-based radar-profiling system positioned with a geodetic L1 GPS receiver (Pattyn and others, 2010). Radio-wave propagation speed in ice is assumed to be $168.4 \mathrm{~m} \mathrm{~s}^{-1}$, which corresponds to permittivity of 3.17. Surface topography was determined by a kinematic GPS survey using a temporary base station located near the crest of the ice promontory. The position of the base station in the International Terrestrial Reference Frame was determined by the Precise Point Positioning method. Earth Gravitational Model 1996 (EGM96) shows that the geoid height is $\sim 24 \mathrm{~m}$ above the World Geodetic System 1984 ellipsoidal elevation (WGS84) in the vicinity of the grounding zone and the floating ice that we surveyed. Therefore, we added $24 \mathrm{~m}$ to the GPS-measured elevations in order to derive elevations relative to regional sea level.

The measured radar power $P_{\text {basal }}$ returned from the base of the ice column is affected by instrumental factors $S$, geometrical factors $G_{\text {basal, two-way englacial attenuation }}$ $L_{\text {ice }}$ and basal reflectivity $R_{\text {basal }}$. The relationship between these factors in the decibel scale $\left([x]_{\mathrm{dB}}=10 \log _{10} x\right)$ can be written as (e.g. Matsuoka and others, 2010)

$$
\left[P_{\text {basal }}\right]_{\mathrm{dB}}=[S]_{\mathrm{dB}}-\left[G_{\text {basal }}\right]_{\mathrm{dB}}-\left[L_{\text {ice }}\right]_{\mathrm{dB}}+\left[R_{\text {basal }}\right]_{\mathrm{dB}} \text {. }
$$

Figure $2 \mathrm{a}$ shows the absence of englacial scatters such as buried crevasses, so losses from $L_{\text {ice }}$ and $G_{\text {basal }}$ are expected to dominate. The ratio of the ice thickness (up to $700 \mathrm{~m}$ ) to the radio-wave wavelength $(\sim 30 \mathrm{~m})$ is small, so extinction of power due to birefringence caused by alignments of ice crystals is probably insignificant (Matsuoka and others, 2009a). Therefore, Equation (1) is a reasonable approximation for our analysis.

The geometric factor $G_{\text {basal }}$ is a function of ice thickness $H$ and depth-averaged permittivity $\varepsilon$ (assumed to be 3.17): $\left[G_{\text {basal }}\right]_{\mathrm{dB}}=2[H / \sqrt{\varepsilon}]_{\mathrm{dB}}$. [ $\left[G_{\text {basal }}\right]_{\mathrm{dB}}$ varies by $\sim 10 \mathrm{~dB}$ for icethickness variations between 200 and $700 \mathrm{~m}$, but it is negligibly affected by possible variations of the depthaveraged permittivity (i.e. density). Therefore, assuming that instrumental factors $S$ remain stable over time, variations in the geometrically corrected returned power $P^{c}$ basal are caused by variations in englacial attenuation and basal reflectivity:

$$
\left[P_{\text {basal }}^{\mathrm{c}}\right]_{\mathrm{dB}} \propto-\left[L_{\text {ice }}\right]_{\mathrm{dB}}+\left[R_{\text {basal }}\right]_{\mathrm{dB}} .
$$




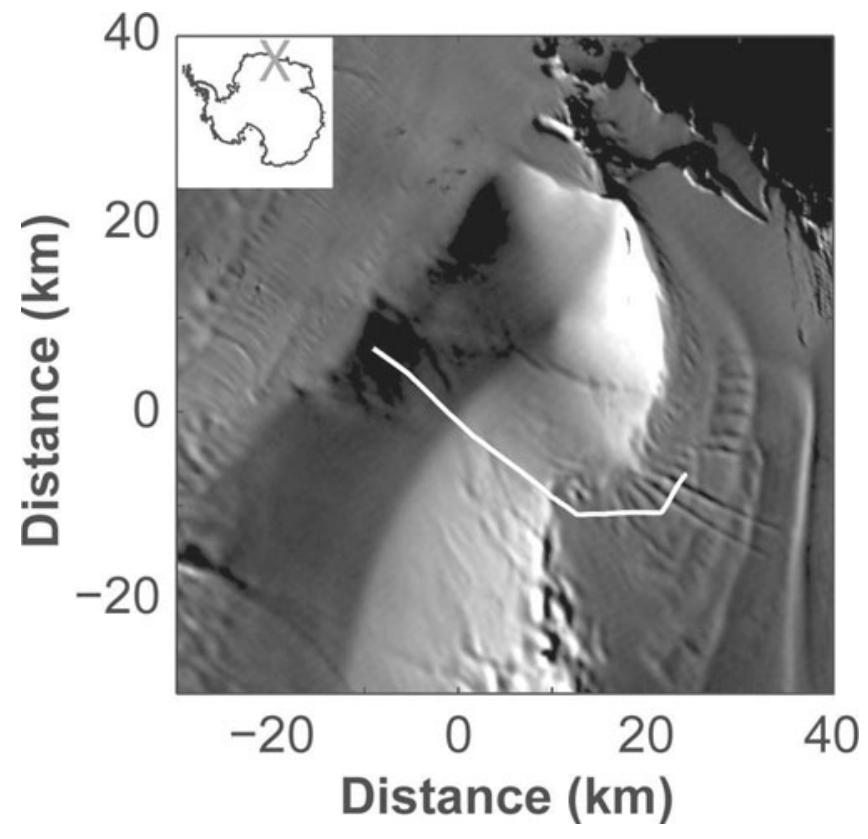

Fig. 1. Study area. The radar profile crosses an ice-rise promontory and the adjacent Roi Baudouin ice shelf in Dronning Maud Land. Background image is a Moderate Resolution Imaging Spectroradiometer (MODIS) satellite mosaic (Haran and others, 2006). Origin of the local coordinate is the site where the radar profile crosses the topographical crest $\left(70.66^{\circ} \mathrm{S}, 23.92^{\circ} \mathrm{E}\right)$. Inset shows the location in Antarctica.

Values for $P^{c}$ basal come from measurements of returned power and ice thickness (calculated from the two-way travel time). Here we derive an accurate estimate $L_{\text {ice }}$ in order to calculate $\left[P^{c} \text { basal }\right]_{\mathrm{dB}}+\left[L_{\mathrm{ice}}\right]_{\mathrm{dB}}$ along the profile, thereby providing a proxy of spatial variations of $\left[R_{\text {basal }}\right]_{\mathrm{dB}}$.

\section{Attenuation estimates}

We estimated depth-averaged englacial attenuation rates in two ways. The first method uses measurements of the geometrically corrected returned power as a function of ice thickness (e.g. Winebrenner and others, 2003; Jacobel and others, 2009). The thickness dependence of the returned power $\left\langle\mathrm{d}\left[P_{\text {basal }}^{c}\right]_{\mathrm{dB}} / \mathrm{d} H\right\rangle$ can be used as a proxy for englacial attenuation if the basal reflectivity is independent of ice thickness, that is when $\left\langle\mathrm{d}\left[R_{\text {basal }}\right]_{\mathrm{dB}} / \mathrm{d} H\right\rangle=0$, $\left\langle\mathrm{d}\left[P_{\text {basal }}^{c}\right]_{\mathrm{dB}} / \mathrm{d} H\right\rangle=\left\langle-\mathrm{d}\left[L_{\text {ice }}\right]_{\mathrm{dB}} / \mathrm{d} H\right\rangle$ (Equation (2)). This method is appropriate when englacial losses (e.g. scattering from buried crevasses) other than $G_{\text {basal }}$ and $L_{\text {ice }}$ are significant (e.g. Raymond and others, 2006).

The second method uses an attenuation model that depends on depth profiles of ice temperature and chemistry. Englacial attenuation is a result of contributions from pure ice, acidity and sea salt in the ice column, which have different temperature dependences. However, the lack of information on depth profiles of chemistry precludes calculating the contributions from acidity and sea salt, and here we consider only the pure-ice contribution. Acidity and sea salt contribute $26 \%$ and $21 \%$ of the total depth-averaged attenuation rate at Siple Dome and Vostok ice-core sites, respectively (Matsuoka and others, 2011). The local oneway attenuation rate $N\left(\mathrm{~dB} \mathrm{~km}^{-1}\right)$ is

$$
N=0.914 \sigma_{\text {pure }} \exp \left[-E_{\text {pure }} / k\left(1 / T-1 / T_{\mathrm{r}}\right)\right] .
$$

Here $\sigma_{\text {pure }}=9.2 \mu \mathrm{s} \mathrm{m}^{-1}, E_{\text {pure }}=0.51 \mathrm{eV}, T_{\mathrm{r}}=251 \mathrm{~K}$ and $k$ is the Boltzmann constant (MacGregor and others, 2007; Matsuoka, 2011). These values have significant uncertainties because there are few published measurements of the temperature dependence of dielectric properties. Consequently, uncertainty in attenuation sensitivity to ice temperature and in estimated attenuation is also large. We ignore this uncertainty in the analysis below.

The ice temperature $T$ for the attenuation model (Equation (3)) is calculated using a two-dimensional (2-D) thermomechanical high-order model (Pattyn, 2002, 2003). The model calculates the horizontal velocity field in the ice sheet using higher-order physics, taking into account vertical shearing as well as longitudinal stress gradient. The velocity fields for both the ice sheet and ice shelf are derived simultaneously. Vertical velocities are obtained from mass conservation and by considering the present-day ice topography in steady state (Hindmarsh, 1999). The velocity field is fully coupled to the temperature field, based on vertical diffusion, horizontal and vertical advection and friction. Flow enhancement factor $m$ is assumed to be uniform at 0.8 or 1.0 . Boundary conditions to the iceflow field are obtained from balance velocity calculations at either side of the profile presented in Figure 2, and a basal friction parameter at the bottom, relating basal velocities to basal shear stress (Pattyn and others, 2006). Basal friction in the ice shelf is set to be zero.

Surface temperature $T_{s}$ over the entire profile and geothermal flux GF over the grounded ice are assumed to be uniform: $T_{\mathrm{s}}=-12^{\circ} \mathrm{C}$ and $\mathrm{GF}=42$ or $54 \mathrm{~mW} \mathrm{~m}^{-2}$. Since the model is not coupled with the ocean, a temperature of $-2^{\circ} \mathrm{C}$, an approximate melting point of sea water corrected for pressure at depth, is prescribed at the ice-water interface of floating ice. In this area, neither measurements nor model estimates of ocean temperature have been made. Surface accumulation rates are determined from the shallowest radar-reflector pattern and a regional mean of the recent accumulation rate of $0.27 \mathrm{~m} \mathrm{a}^{-1}$ from a continental mass-balance model (Pattyn and others, in press). For each geothermal flux and flow-enhancement factor, the model was run more than 20000 years until the ice-flow and temperature fields reached a steady state.

The radar transect across the ice promontory was aligned perpendicular to surface contours, which is an approximation of the ice-flow direction. However, the radar transect on the ice shelf may deviate from the flowline. There are no depth variations of ice-flow speed over the ice shelf (plug flow), so the vertical velocity profile is linear so that the steady-state depth profile of temperature is a function of vertical advection rates and constrained by the upper and lower surface temperatures, regardless of the upstream ice-flow field (e.g. Hindmarsh, 1999). Therefore, the effects of transverse stress coupling and the deviation of the radar profile from the true flowline on the estimated temperature field are expected to be small, as horizontal (advection) effects are negligible.

\section{RESULTS AND DISCUSSION}

\section{Radar and GPS measurements}

Figure 2a shows a radargram with surface elevation adjustments using GPS-measured surface elevations $z_{\mathrm{s}}$. Figure $2 \mathrm{~b}$ shows details of the surface topography in the vicinity of the grounding zone, and Figure 2c shows $\delta z=z_{\mathrm{s}}-z_{\text {float, }}$ where 


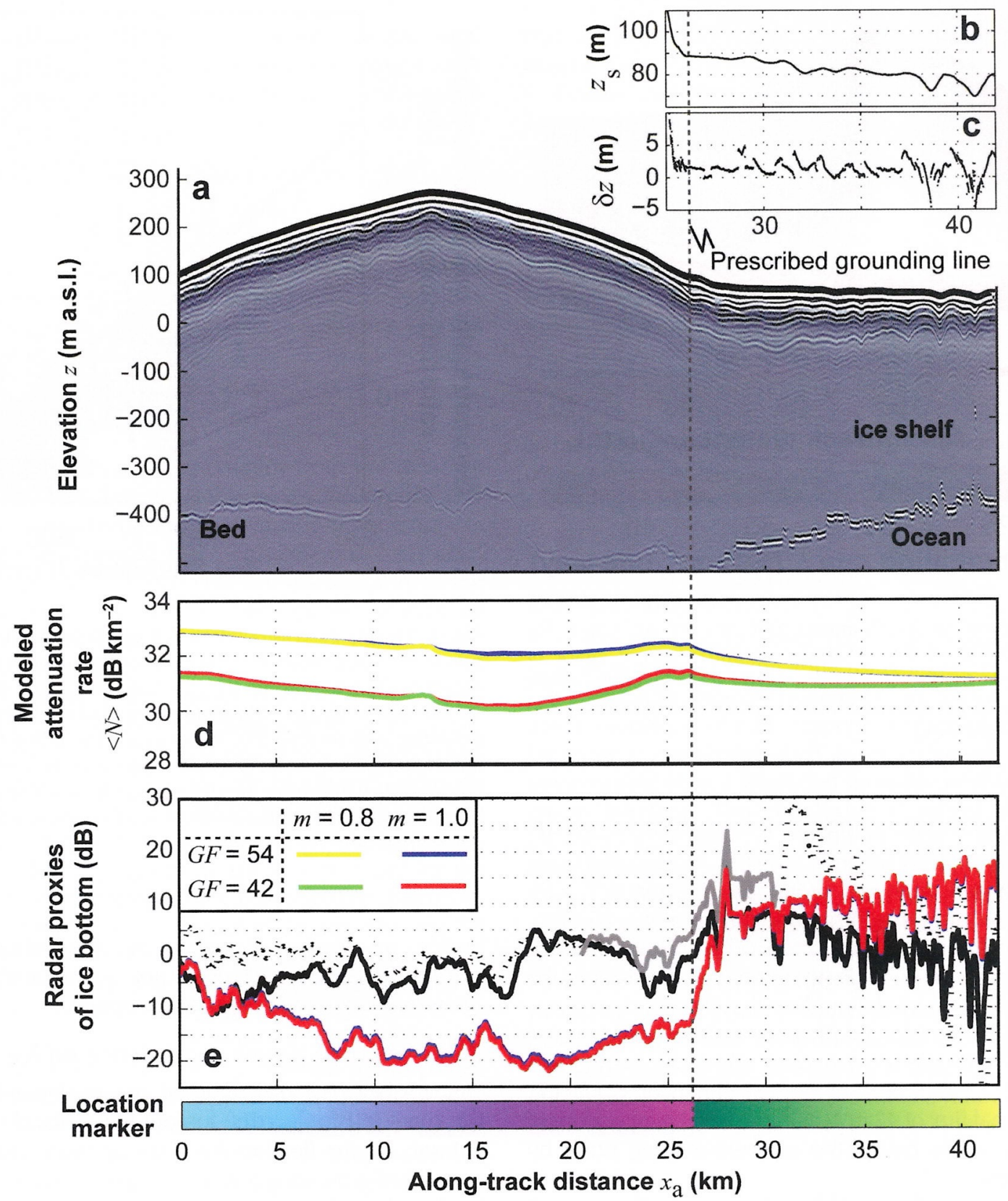

Fig. 2. Observed and modeled properties along the radar profile. The location marker is referred to in Figure 4. (a) Radargram is adjusted to account for surface elevation variations. (b) Detailed surface topography of the grounding zone and floating ice. (c) $\delta z=z_{\mathrm{s}}-z_{\mathrm{float}}$ where $z_{\mathrm{s}}$ is the measured ice-surface elevation and $z_{\text {float }}$ is the thickness of freely floating ice (Equation (4)). Vertical gray dashed line shows where ice becomes freely floating. (d) Depth-averaged attenuation rates $\langle N\rangle$ estimated using ice-flow models for geothermal fluxes GF $=42$ and $54 \mathrm{~mW} \mathrm{~m}^{-2}$ and for ice-flow enhancement factors $m$ of 0.8 and 1.0. Results for different $m$ are nearly identical. Color legend is as shown in (e). (e) Estimated relative reflectivity $\left[R_{\text {basal }}\right]_{\mathrm{dB}}$ using attenuation models. Also shown are anomalous basal returned power $\left(\Delta\left[P^{c} \text { basal }\right]_{\mathrm{dB}}\right)$ values (Equation (5)) estimated using a widely used radar method for four data ensembles (Fig. 4): the black solid curve is for the entire dataset, the two dashed curves are for grounded and floating ice, respectively, excluding the vicinity $(5 \mathrm{~km})$ of the grounding line, and the gray curve is for the vicinity $( \pm 5 \mathrm{~km})$ of the grounding line. $\left[R_{\text {basal }} l_{\mathrm{dB}}\right.$ and $\Delta\left[P^{c}\right.$ basal $l_{\mathrm{dB}}$ shown here are filtered with a $1 \mathrm{~km}$ running average.

$z_{\text {float }}$ is the thickness of freely floating ice that can be derived from the ice thickness $H$ and densities of ice $\rho_{\mathrm{i}}$ and of ocean water $\rho_{\mathrm{w}}$ :

$$
z_{\text {float }}=\left(\rho_{\mathrm{w}}-\rho_{\mathrm{i}}\right) / \rho_{\mathrm{w}} \times H .
$$

When ice is in hydraulic equilibrium (and all $\rho_{\mathrm{i}}, \rho_{\mathrm{w}}$ and $H$ are accurate), $\delta z$ is zero. In earlier work we showed that $\delta z$ is minimal over the downstream side $\left(x_{\mathrm{a}}>25.6 \mathrm{~km}\right)$ of this profile (Pattyn and others, in press. At landward sites $\left(x_{a}<25.6 \mathrm{~km}\right), \delta z$ increases rapidly, so the ice is no longer in hydrostatic equilibrium. Therefore, we determined that the most landward site of freely floating ice is at $x_{\mathrm{a}}=25.6 \mathrm{~km}$.

We did not find a topographic minimum or a break in slope associated with the non-hydrostatic ice flexure response typically found in grounding zones (Brunt and others, 2010). Although our repeat GPS profiles between the ice promontory and the ice shelf do show some changes in elevation at sites landward of freely floating ice, they do not allow us to determine the most landward site affected by tidal forcing. 


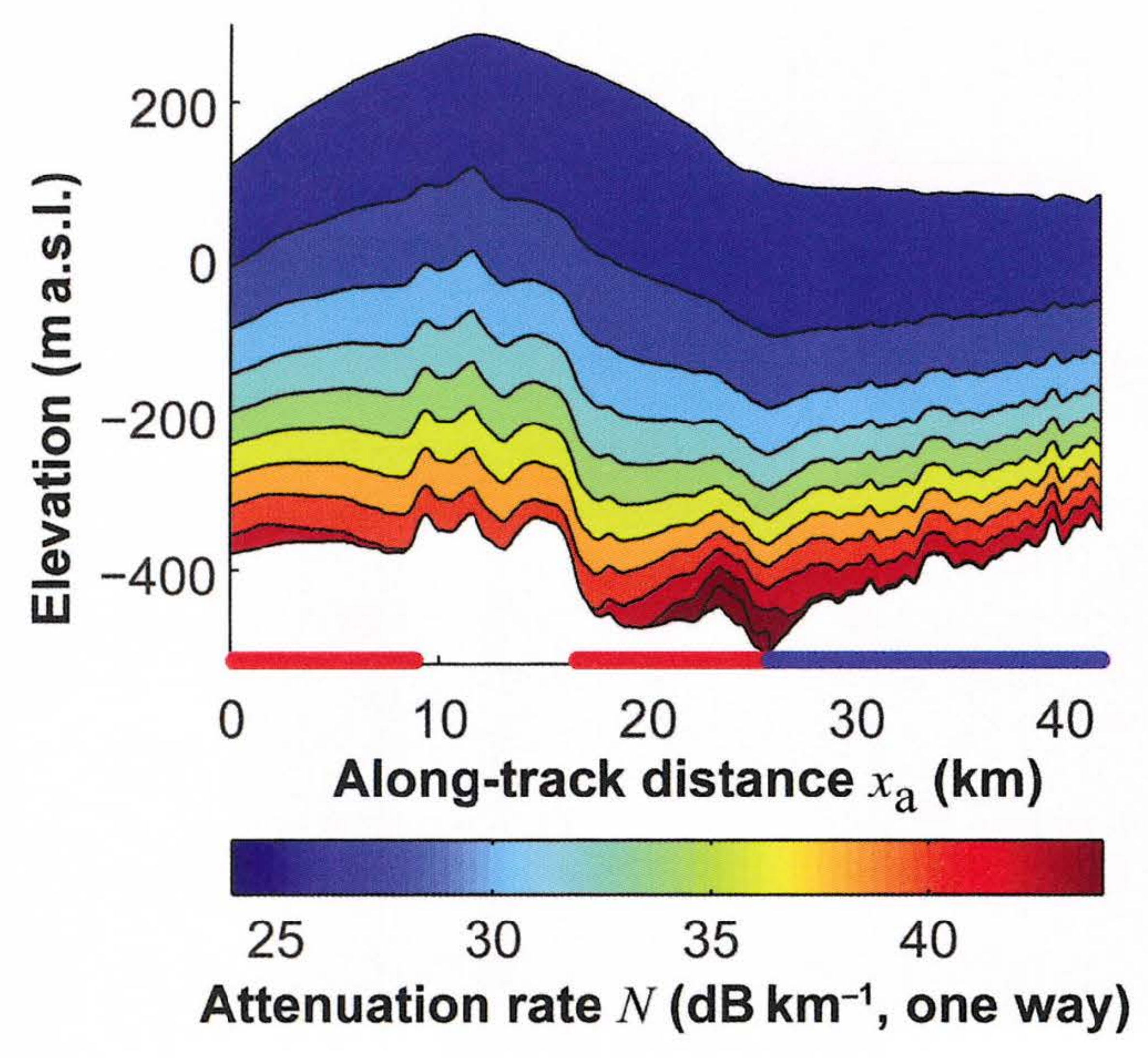

Fig. 3. Variations in local attenuation rate $N$ estimated for geothermal flux of $54 \mathrm{~mW} \mathrm{~m}^{-2}$ and flow-enhancement factor of 1.0. Red and blue markers along the abscissa show locations where the basal ice is at the (pressure-)melting point over grounded and floating ice, respectively.

\section{Attenuation estimates using thermomechanical model}

Figure 3 shows englacial attenuation rates $N$ estimated using the thermomechanical model for $(\mathrm{GF}, m)=\left(54 \mathrm{~mW} \mathrm{~m}^{-2}, 1.0\right)$. In the model, we prescribe the grounding line at $x_{\mathrm{a}}=25.6 \mathrm{~km}$, although in reality it is slightly landward of this position. Ice temperature increases with depth monotonically, as does the attenuation rate. The model predicts that the basal temperature of grounded ice is at the pressure-melting point, except for the vicinity of the ice-rise crest when the geothermal flux is $54 \mathrm{~mW} \mathrm{~m}^{-2}$ regardless of the flow-enhancement factor. For a geothermal flux of $42 \mathrm{~mW} \mathrm{~m}^{-2}$, the basal temperature of the grounded ice is below the pressure-melting point by several degrees.

Figure $2 \mathrm{~d}$ shows the spatial pattern of depth-averaged attenuation rate $\langle N\rangle$, which is derived by integrating local attenuation rates $N$ (Fig. 3) vertically at sites along the profile. Total attenuation $\left[L_{i c e}\right]_{\mathrm{dB}}$ is proportional to the ice thickness $H$ and the depth-averaged attenuation rate $\langle N\rangle$ : $\left[L_{\text {ice }}\right]_{\mathrm{dB}}=2\langle\mathrm{~N}\rangle H$ [ (the factor of 2 is to account for the twoway travel). Although $\langle N\rangle$ increases with geothermal flux GF and decreases with flow-enhancement factor $m$, the amplitudes of $\langle N\rangle$ variations along the profile are 1.3$1.7 \mathrm{~dB} \mathrm{~km}^{-1}$ and the spatial pattern remains similar regardless of GF and $m$ (Fig. 2d). Differences in the flowenhancement factors have negligible effects on $\langle N\rangle$.

It is still an open question whether the temperature in Equation (3) is relative to the pressure-melting point, because all dielectric properties used to determine $\sigma_{\text {pure }}$ and $E_{\text {pure }}$ were measured with meteoric or laboratory-grown ice at the standard atmospheric pressure, so the (pressure-) melting point of the ice specimen for those measurements is close to $0^{\circ} \mathrm{C}$. If an attenuation approximation (Equation (3)) is more appropriate for temperature relative to the pressuremelting point, then the estimated variations in $\langle N\rangle$ over the shelf ice would be larger than those shown in Figure 2 by $\sim 1 \mathrm{~dB} \mathrm{~km}^{-1}$. This difference is nearly uniform along the

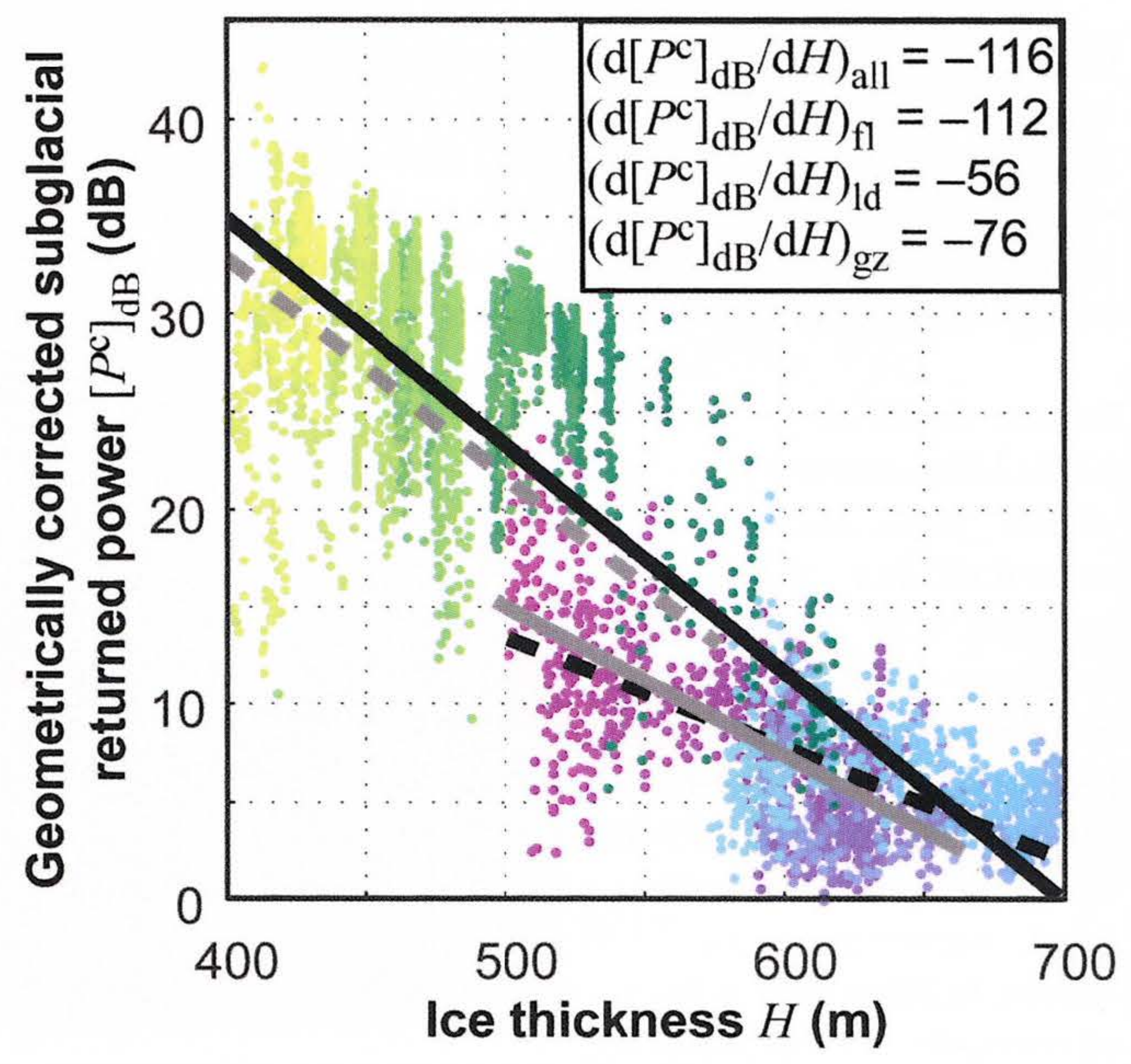

Fig. 4. Ice-thickness dependence of geometrically corrected radar power returned from the basal interface. Colors represent the location along the profile (Fig. 2). Solid black line shows linear fit for the entire dataset. Black and gray dashed lines show fits for grounded and floating ice, respectively, excluding the groundingline vicinity $(5 \mathrm{~km})$. Solid gray line shows fit in the vicinity $( \pm 5 \mathrm{~km})$ of the grounding line. Inset shows the slope of these lines (unit: $\mathrm{dB} \mathrm{km}^{-1}$ for round trip); half of these values are frequently used as one-way attenuation rate $\langle N\rangle$.

profile, so this uncertainty in the attenuation parameterization (Equation (3)) does not significantly affect our interpretations of the basal environment.

\section{Basal returned power dependence on ice thickness}

Figure 4 shows basal returned power dependence on ice thickness $\left\langle\mathrm{d}\left[P_{\text {basal }}^{c}\right]_{\mathrm{dB}} / \mathrm{d} H\right\rangle$ for four linear fits: (1) for the entire dataset; (2) for floating ice $5 \mathrm{~km}$ or more seaward of the prescribed grounding line; (3) for grounded ice $5 \mathrm{~km}$ or more landward of the grounding line; and (4) in the vicinity $( \pm 5 \mathrm{~km})$ of the grounding line. The attenuation rate $\langle N\rangle$ $\left(=-\left\langle\mathrm{d}\left[P_{\text {bed }}^{c}\right]_{\mathrm{dB}} / \mathrm{d} H\right\rangle / 2\right)$ varies by a factor of 2 , depending on the choice of data ensembles used in the fit (Fig. 4): $58 \mathrm{~dB} \mathrm{~km}^{-1}$ (all data), $56 \mathrm{~dB} \mathrm{~km}^{-1}$ (floating ice), $38 \mathrm{~dB} \mathrm{~km}^{-1}$ (grounding zone) and $28 \mathrm{~dB} \mathrm{~km}^{-1}$ (grounded ice). In contrast, results from the temperature-dependent attenuation model (Equation (3)) indicate relatively uniform depth-averaged values, $30-33 \mathrm{~dB} \mathrm{~km}^{-1}$ (Fig. 2d). As discussed earlier, the temperature-dependent attenuation model used here does not account for contributions from ice chemistry, which could increase these calculated $\langle N\rangle$ by $\sim 10 \mathrm{~dB} \mathrm{~km}^{-1}$ if sea salt of $17 \mu \mathrm{mol} \mathrm{L}^{-1}$ is included in the ice.

The thickness dependence of the basal returned power does not give a regional mean attenuation rate when the attenuation rates vary significantly in the data ensemble or the bed reflectivity depends on ice thickness (Matsuoka, 2011). Along our profile, the attenuation rate estimated from the attenuation temperature model is nearly uniform within $\pm 1 \mathrm{~dB} \mathrm{~km}^{-1}$ (Fig. 2d). However, the grounded ice is generally thicker than the floating ice, and a significant thickness variation is found in the floating ice (Fig. 4; color of markers show the locations along the profile (see Fig. 2)). These 
features yield apparent thickness dependence of the basal reflectivity, which is a likely reason why attenuation rates estimated with the thickness dependences of the basal returned power do not match well with the model estimates.

\section{Inferring conditions at the basal interface}

Although the radar instrument factor is unknown, the transmitter used here is known to be stable (Matsuoka and others, 2009b). So, $\left[P^{c} \text { basal }\right]_{\mathrm{dB}}+\left[L_{\mathrm{ice}}\right]_{\mathrm{dB}}$ provides a proxy of spatial variations of $\left[R_{\text {basal }}\right]_{\mathrm{dB}}$ (Equation (1)). The anomalous basal returned power $\Delta\left[P^{c} \text { basal }\right]_{\mathrm{dB}}$ from values predicted with the traditional radar method (Fig. 4) also provides a proxy of spatial variations of $\left[R_{\text {basal }}\right]_{\mathrm{dB}}$ :

$$
\Delta\left[P_{\text {basal }}^{\mathrm{C}}\right]_{\mathrm{dB}}=\left[P_{\text {basal }}^{\mathrm{C}}\right]_{\mathrm{dB}}-\left\langle\mathrm{d}\left[P_{\text {basal }}^{\mathrm{C}}\right]_{\mathrm{dB}} / \mathrm{d} H\right\rangle H .
$$

Figure 2e shows $\Delta\left[P^{c} \text { basal }\right]_{\mathrm{dB}}$ anomalies from the mean of $\Delta\left[P^{c} \text { basal }\right]_{\mathrm{dB}}$ for each data ensemble along the profile as a proxy of relative basal reflectivity. Attenuation-rate estimates depend on the geothermal flux (Fig. 2d), but the spatial patterns of $\left[R_{\text {basal }}\right]_{\mathrm{dB}}$ estimated here are not sensitive to the magnitude of the geothermal flux because the 'pattern' of $\langle N\rangle$ is controlled primarily by the 'pattern' of ice thickness and accumulation rate.

Figure $2 \mathrm{e}$ shows four distinct features in $\left[R_{\text {basal }}\right]_{\mathrm{dB}}$ estimated with attenuation modeling and in $\Delta\left[P^{c} \text { basal }\right]_{\mathrm{dB}}$. First, $\Delta\left[P^{c} \text { basal }\right]_{\mathrm{dB}}$ for the entire dataset show similar values for the grounded ice and floating ice in general, although basal conditions for the grounded and floating ice are presumably distinct. Near the profile end on the floating ice $\left(x_{\mathrm{a}}>\sim 35 \mathrm{~km}\right), \Delta\left[P^{c} \text { basal }\right]_{\mathrm{dB}}$ for the entire profile and for the floating ice are smaller than for the grounded ice. However, radar-measured ice thickness gives surface elevation for the freely floating ice consistent with the GPS-measured elevation over this area (Fig. 2b). The presence of marine ice is therefore unlikely, and basal conditions should be more or less constant over the floating ice. Also, attenuation estimates used for these $\Delta\left[P^{c} \text { basal }\right]_{\mathrm{dB}}$ over the entire profile and over the floating ice are extremely high $\left(56-58 \mathrm{~dB} \mathrm{~km}^{-1}\right.$ for one way). Therefore, we conclude that these $\Delta\left[P^{c} \text { basal }\right]_{\mathrm{dB}}$ values for the entire dataset and for the floating ice do not represent variations in the basal conditions.

Second, $\Delta\left[P_{\text {basal }}^{c}\right]_{\mathrm{dB}}$ for the grounding-line vicinity varies $\sim 20 \mathrm{~dB}$. This variation happens in the horizontal distance of $\sim 5 \mathrm{~km}$. A similar feature is found in $\left[R_{\text {basal }}\right]_{\mathrm{dB}}$ estimated with attenuation modeling. In the grounding-line vicinity, the modeling predicts an attenuation variation less than $1 \mathrm{~dB}$ $\mathrm{km}^{-1}$ for one way; the ice thickness varies $<150 \mathrm{~m}$ in this area, giving minimal variations in the total attenuation $\left[L_{\mathrm{ice}}\right]_{\mathrm{dB}}$ within the grounding zone. Thus, the predicted variations in $\left[R_{\text {basal }}\right]_{\mathrm{dB}}$ are essentially identical to variations in $\left[P_{\text {basal }}^{\mathrm{C}}\right]_{\mathrm{dB}}$. In practice, basal reflectivity is insensitive to the attenuation estimates in such areas where the ice thickness and attenuation rate vary little.

Third, $\left[R_{\text {basal }}\right]_{\mathrm{dB}}$ estimated with attenuation modeling has a broad minimum near the crest $\left(x_{a}=\sim 12 \mathrm{~km}\right)$. It becomes larger towards both ends of the profile over the grounded ice. This pattern is also found in the modeled basal temperature, when geothermal flux is $54 \mathrm{~mW} \mathrm{~m}^{-2}$ (Fig. 3). The range of $\left[R_{\text {basal }}\right]_{\mathrm{dB}}$ over the grounded ice is $\sim 20 \mathrm{~dB}$ from the crest to the western end of the profile and $10 \mathrm{~dB}$ from the crest to the grounding line. However, basal reflectivity is related to the local amount of water, rather than local melting rate, so our 2-D modeling cannot be used to constrain the flow-model parameters such as geothermal flux, which alter the ice temperature, using the pattern of the observed bed reflectivity.

Finally, variations of $\Delta\left[P^{c} \text { basal }\right]_{\mathrm{dB}}$ depend on data ensembles used for constructing the fit between returned power and ice thickness (Fig. 4). For example, $\left\langle\mathrm{d}\left[P_{\text {basal }}^{\mathrm{c}}\right]_{\mathrm{dB}} / \mathrm{d} H\right\rangle H$ derived for the floating ice is -144 or $-112 \mathrm{~dB} \mathrm{~km}^{-1}$ when the data ensemble includes or excludes, respectively, the $5 \mathrm{~km}$ portion of the profile close to the grounding line. However, $\left\langle\mathrm{d}\left[P_{\text {basal }}^{\mathrm{c}}\right]_{\mathrm{dB}} / \mathrm{d} H\right\rangle H$ derived for the grounded ice varies only $3 \mathrm{~dB} \mathrm{~km}^{-1}$ if the data ensemble includes or excludes the grounding-line vicinity. Therefore, the analysis of the spatial pattern of $\Delta\left[P^{c} \text { basal }\right]_{\mathrm{dB}}$ is not rigorous. $\left[R_{\text {basal }}\right]_{\mathrm{dB}}$ derived from four modeled temperature-dependent attenuation rates show similar spatial patterns (Fig. 2e). These results suggest that basal conditions revealed by the temperature-dependent attenuation modeling are robust despite uncertainties in the modeling parameters and boundary conditions.

\section{CONCLUSIONS}

A sharp increase in basal reflectivity was found in the vicinity of the grounding zone using a temperature-dependent attenuation model in combination with a thermomechanical model to estimate temperature profiles in the ice. This increase is consistent with a step change in the basal environment from a grounded (possibly wet) bed to an iceocean interface. This conclusion is robust even with the inherent uncertainties in the model, such as geothermal flux, flow-enhancement factor and location of the grounding line. Such a step change is also detected using a traditional radar method that assumes uniform attenuation rate, probably because variations in attenuation in this area are minimal. However, the radar method and temperature-dependent modeling give distinctly different patterns of anomalous basal reflectivity over the grounded ice and over the floating ice. The results argue strongly for a temperature-dependent attenuation model, when the radar returned power is analyzed to extract a proxy of basal conditions.

\section{ACKNOWLEDGEMENTS}

We acknowledge logistic support from the Belgian Antarctic Research Expedition (BELARE). This project was supported by the Belgian Federal Science Policy Office (grant No.: EA/ $11 / 3 \mathrm{~A}$ ), the University of Washington Royalty fund (grant No.: 4208) and the Center for Ice, Climate and Ecosystems at the Norwegian Polar Institute. We are indebted to A. Hubert, R. Wagemans, K. Soete and other BELARE field participants for assistance in the field. D.C. is funded by an FNRS-FRIA scholarship and by the YGGDRASIL mobility program, Research Council of Norway. Comments by Sasha Carter, an anonymous reviewer and the scientific editor, Poul Christoffersen, improved the paper significantly.

\section{REFERENCES}

Brunt KM, Fricker HA, Padman L, Scambos TA and O'Neel S (2010) Mapping the grounding zone of Ross Ice Shelf, Antarctica, using ICESat laser altimetry. Ann. Glaciol., 51(55), 71-79

Fricker HA and Padman L (2006) Ice-shelf grounding zone structure from ICESat laser altimetry. Geophys. Res. Lett., 33(15), L15502 (doi: 10.1029/2006GL026907) 
Haran T, Bohlander J, Scambos T, Painter T and Fahnestock $M$ (2006) MODIS mosaic of Antarctica (MOA) image map. National Snow and Ice Data Center, Boulder, CO. Digital media

Hindmarsh RCA (1999) On the numerical computation of temperature in an ice sheet. J. Glaciol., 45(151), 568-574

Jacobel RW, Welch BC, Osterhouse D, Pettersson R and MacGregor JA (2009) Spatial variation of radar-derived basal conditions on Kamb Ice Stream, West Antarctica. Ann. Glaciol., 50(51), 10-16

MacGregor JA, Winebrenner DP, Conway $\mathrm{H}$, Matsuoka K, Mayewski PA and Clow GD (2007) Modeling englacial radar attenuation at Siple Dome, West Antarctica, using ice chemistry and temperature data. J. Geophys. Res., 112(F3), F03008 (doi: 10.1029/2006JF000717)

MacGregor JA, Anandakrishnan S, Catania GA and Winebrenner DP (2011) The grounding zone of the Ross Ice Shelf, West Antarctica, from ice-penetrating radar. J. Glaciol., 57(205), 917-928

Matsuoka K, Gades A, Conway H, Catania G and Raymond C (2009a) Radar signatures beneath a surface topographic lineation near the outlet of Kamb Ice Stream and Engelhardt Ice Ridge, West Antarctica. Ann. Glaciol., 50(51), 98-104

Matsuoka K, Wilen L, Hurley SP and Raymond CF (2009b) Effects of birefringence within ice sheets on obliquely propagating radio waves. IEEE Trans. Geosci. Remote Sens., 475(5), 1429-1443

Matsuoka K, Morse D and Raymond CF (2010) Estimating englacial radar attenuation using depth profiles of the returned power, central West Antarctica. J. Geophys. Res., 115(F2), F02012 (doi: 10.1029/2009JF001496)

Matsuoka K (2011) Pitfalls in radar diagnosis of ice-sheet bed conditions: lessons from englacial attenuation models. Geophys. Res. Lett., 38(5), L05505 (doi: 10.1029/2010GL046205)

Matsuoka K, MacGregor JA and Pattyn F (2011) Using englacial radar attenuation to better diagnose the subglacial environment: a review. In Crocco L ed. Proceedings of the 13th International Conference on Ground Penetrating Radar (GPR), 21- 25 June
2010, Lecce, Italy. Institute of Electrical and Electronics Engineers, Piscataway, NJ, 1-5

Pattyn F (2002) Transient glacier response with a higher-order numerical ice-flow model. J. Glaciol., 48(162), 467-477

Pattyn F (2003) A new three-dimensional higher-order thermomechanical ice-sheet model: basic sensitivity, ice stream development, and ice flow across subglacial lakes. J. Geophys. Res., 108(B8), 2382

Pattyn F, Huyghe A, de Brabander S and De Smedt B (2006) Role of transition zones in marine ice sheet dynamics. J. Geophys. Res. 111(F2), F02004 (doi: 10.1029/2005JF000394)

Pattyn F, Matsuoka K and Berte J (2010) Glacio-meteorological conditions in the vicinity of the Belgian Princess Elisabeth Station, Antarctica. Antarct. Sci., 22(1), 79-85

Pattyn $\mathrm{F}$ and 8 others (in press) Radar and ice-core evidence for active ice-ocean interaction under the Roi Baudouin Ice Shelf, East Antarctica. J. Geophys. Res. Earth Surf.

Raymond CF, Catania GA, Nereson N and Van der Veen CJ (2006) Bed radar reflectivity across the north margin of Whillans Ice Stream, West Antarctica, and implications for margin processes. J. Glaciol., 52(156), 3-10

Schoof C (2007) Ice-sheet grounding-line dynamics: steady states, stability, and hysteresis. J. Geophys. Res., 112 (F3), F03S28 (doi: 10.1029/2006JF000664)

Sykes HJ, Murray T and Luckman A (2009) The location of the grounding zone of Evans Ice Stream, Antarctica, investigated using SAR interferometry and modelling. Ann. Glaciol., 50(52), 35-40

Vaughan DG (1994) Investigating tidal flexure on an ice shelf using kinematic GPS. Ann. Glaciol., 20, 372-376

Winebrenner DP, Smith BE, Catania GA, Conway HB and Raymond CF (2003) Radio-frequency attenuation beneath Siple Dome, West Antarctica, from wide-angle and profiling radar observations. Ann. Glaciol., 37, 226-232 